\title{
Segmental definition: Part I. A focal point for diagnosis of somatic dysfunction
}

WILLIAM L. JOHNSTON, D. FAAO

East Lansing, Michigan

This paper gives a scientific foundation for palpatory diagnosis through the description of specific palpatory tests and the use of criteria for judging the responses to the tests. In the descriptive and clinical research studies summarized here, the somatic structures are examined as a mobile system. A series of rotary and translatory movement tests provide a pattern for examination of function of mobile bony segments. A primary segmental dysfunction is identified by asymmetric responses to opposing directions of each motion test and the presence of mirror image asymmetries in immediately adjacent segments. Thus, the location of segmental dysfunction is verified by comparison of asymmetries within a dysfunctional unit involving three spinal segments. The diagnostic site of the primary segmental asymmetry provides the physician with a specific locus for treatment of somatic dysfunction. New information from the motion tests suggests reassessment of previously held concepts of segmental dysfunction.

A clearly defined focus for the principled application of an osteopathic manipulative procedure has been historically elusive. Careful definition of the location and distinguishing characteristics of those segmental aspects of somatic dysfunction fundamental to the clinical use of osteopathic manipulative procedures is needed. In palpatory diagnosis, a precise spinal segmental level is lo- calized where the findings of local dysfunction are more noticeable and more clinically significant. In the past, descriptions of the palpable features of segmental dysfunction have included alterations in bony position, soft tissue fluid content, muscular tone, and joint mobility ${ }^{1}$. In view of the frequency with which these kinds of changes, individually, can be palpated throughout the musculoskeletal system, the terms have been somewhat nonspecific. The problem is to distinguish the many areas of compensatory (secondary) or minor alterations from those fewer primary areas of more major dysfunction that are focused at precise spinal levels. Terms such as "arthritis," "myositis," "fasciitis," and "neuritis" are convenient to refer to inflammation in separate tissue components of the somatic system, but they are inadequate to describe the clinical condition reflected by disturbance in each of these tissues, in concert, at a dysfunctional spinal segment.

This report has been organized from mainly descriptive clinical investigations which formed the basis for studies with instrumental measurements at Michigan State University-College of Osteopathic Medicine and at Chicago College of Osteopathic Medicine. Part I concentrates on the way the body's response is monitored during selected movement tests to elicit more precise diagnostic signs of the segmental dysfunction as shown by palpable features of altered mobility. Information about asymmetries in segmental motion help to clarify a basis for the procedural approaches to osteopathic manipulative management of somatic dysfunction; an example will be explored in Part II. Finally, in Part III, segmental definition ${ }^{2,3}$ of asymmetric response to motion tests will be used to facilitate the differential diagnosis of somatic dysfunction, and to distinguish somatic findings of somatic reflex origin from those of visceral reflex origin. 


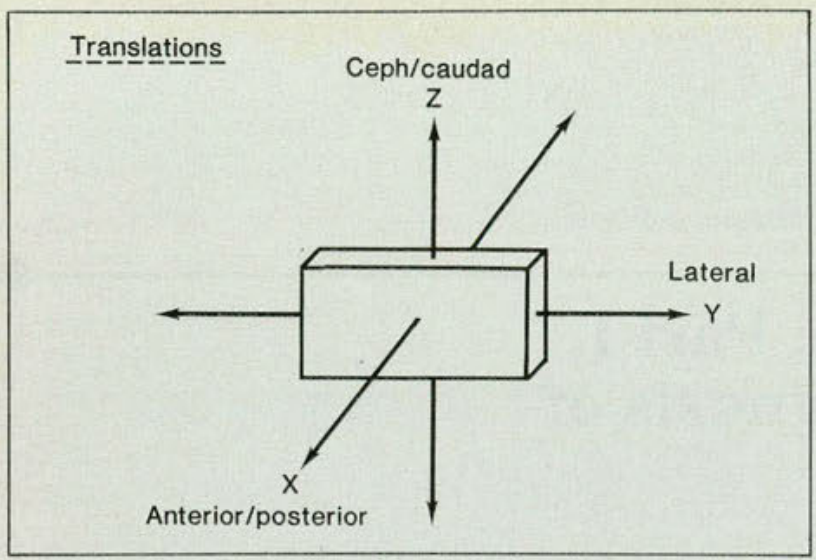

Fig. 1. A coordinate system to illustrate straight-line directions of movement, used in description of translatory motion tests.

\section{Rotations}

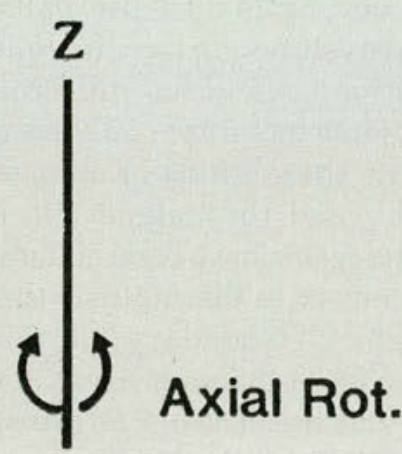

Flex./Ext.
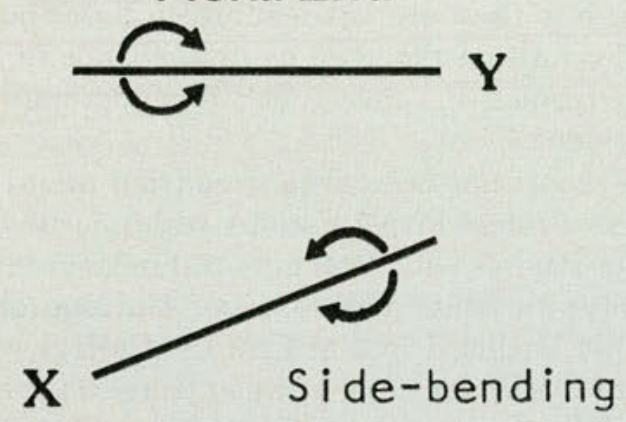

Fig. 2. A coordinate system to illustrate directions of movement about axes, used in description of rotary motion tests.

\section{Procedure}

In formulating tests of the body's movement system, attention first was given to a classification of body movements whose eventual description would be in relation to the coordinates or axes about which movement of an object can be described. There are three degrees of freedom for translatory movement (Fig. 1). These include straight-line movements along the coordinates $z$ (up/down), $y$ (right/left), and $x$ (anterior/posterior). In addition, there are three degrees of freedom for rotations, as illustrated in Figure 2: axial rotation about the vertical $z$ axis; forward flexion/extension about $y$; sidebending or lateral flexion about the $x$ axis. These six kinds of passive gross movement are the "tools" used for testing the body's response to movement.

Such a classification provides a foundation for improving clinical communication about tests for symmetry and range of body movement. Basic modes of everyday body movement can be reproduced in a series of tests for obtaining clinical information, not only about overall performance of the whole movement, ${ }^{4}$ but especially about the local behavior of the mobile parts during the movement. ${ }^{5}$ Passive movement, introduced by the examiner, is used (1) to minimize active interference by the patient, (2) standardize the procedure for the examiner, and (3) contribute to reliability for clinical use and for research.

In the description of these test procedures, certain points of reference are necessary. The position of the subject must be clearly established (seated, supine, or other). Where is motion being introduced by the examiner-for example, through contact at the head, shoulders, extremities? Where does the examiner stand in relation to the subject? Where is palpatory contact established for monitoring a segment's response to the motion being introduced?

In testing the response of each body region (rather than each segment) to gross motions, the criteria for a palpable finding of asymmetry are not measured visually at the endpoint of range, after the response has taken place. ${ }^{4}$ Instead, criteria have been established for the palpable quality of the response within the range, and for the quality of the endpoint. Resistance to gross movement, palpated earlier in one direction than in the opposite, is a tentative sign of the presence of dysfunction in the somatic region being tested. ${ }^{6,7}$ These regional tests screen overall response to motion for a first impression of the presence of a clinical problem in the mobile system.

When passive gross motion tests are applied to monitor behavior of a segment, the criteria for response are concerned with palpable findings at a single mobile segment. The bony part moves in a manner that is controlled by the feedback of information about the quality of that response from its own adnexal tissues and adjacent segments. ${ }^{8}$ On the basis of this feedback, the response is self-correcting for minor readjustments, while the movement is occurring, so that the resulting behavior of the mobile segment will match the demands of the whole movement.

From an appreciation of this feedback mecha- 

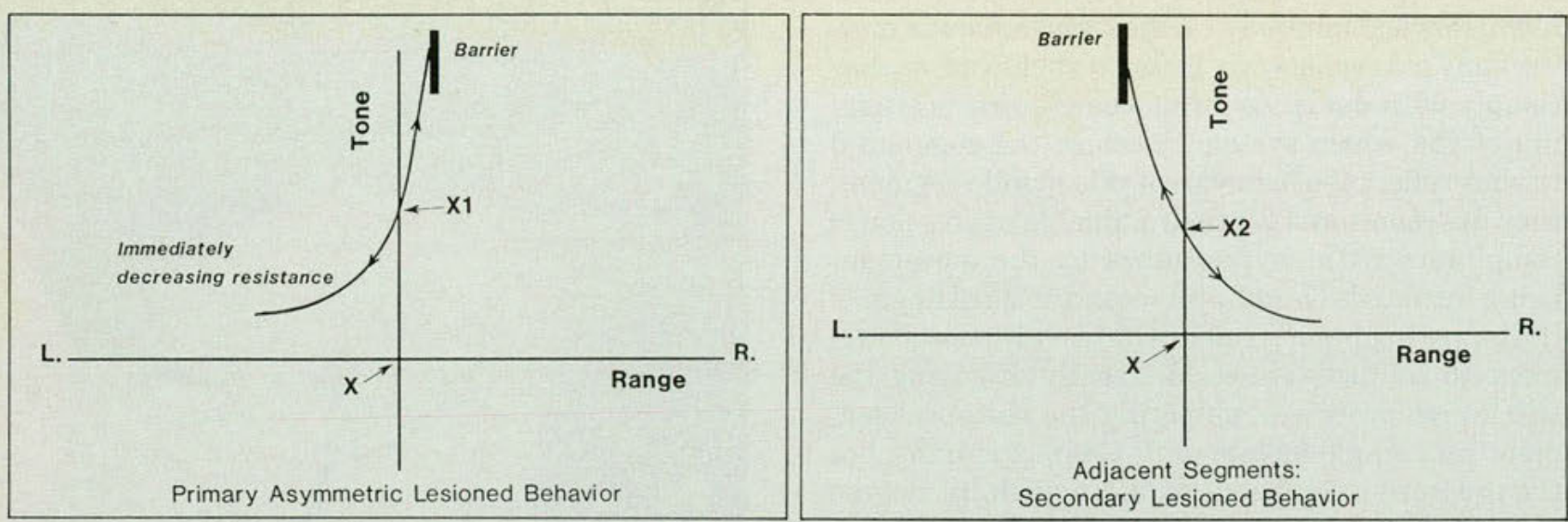

Fig. 5. Schematic representation for asymmetric behavior at a dysfunctional (lesioned) segment: Palpable increase in resistance to pressure (at rest) reflects an elevated level on the tension scale at X1. As indicated, immediately increasing resistance is met in the direction toward the barrier sensed in rotation to the right, and immediately decreasing resistance, toward the left. Fig. 6 . Schematic representation for response to rotation tests at adjacent segments: Secondary lesioned behavior is indicated by an asymmetry with increasing resistance toward the left and increasing compliance toward the right, that is, in opposing directions to the example of primary dysfunction illustrated in Figure 5.

compliance, then an eventual endpoint resistance. During gross axial rotation, similar segmental responses to rotation right and left express a functional symmetry.

The example in Figure 4 serves as a graphic representation for all six kinds of movement; the proportions of the compliance and resistance phases will vary with different movements and in the different regions of the body. Both bony and soft tissues of a segment reflect these palpable cues about compliance and resistance during tests for response to motion. This example describes symmetric, or nonlesioned, segmental behavior.

The characteristics of lesioned behavior in response to movement are illustrated in Figure 5. The resting tissues at a lesioned segment express the disturbed function even before movement is initiated, as demonstrated by their increased resistance to palpatory pressure; this is illustrated on the diagram by the higher position on the tension scale at $x 1$. During rotation right in this example, there may be no compliant phase; the tissues express an immediately increasing resistance, with the endpoint arriving soon. During rotation left, the tissues express an immediately decreasing resistance and increasing compliance; the endpoint in this opposing direction comes much later.

As an example, again, Figure 5 represents graphically the asymmetric response to motion that is palpable at a lesioned segment during all six directions of motion tested (three rotations and three translations). Our investigations indicate that segmental $d y s$ function is expressed by a complete asymmetry in the six degrees of freedom.

This dysfunction does not exist as an isolated finding among normally functioning segments. Immediately adjacent segments also show a palpable increase in tissue resistance to some directions of initial movement. ${ }^{3,10}$ As indicated in Figure 6, the tissue resistance of the two adjacent segments (at rest) is not quite as high on the tension scale at $x 2$. Also, they express asymmetry in response to motion, but, significantly, the resistance is in directions of motion opposite those of the more centrally located lesioned segment. At the adjacent segments, their increasing resistance is in response to rotation left rather than right in the central segment, and the tissues demonstrate initial increasing compliance during rotation right. There is, predictably, a complete opposing asymmetry in response to tests of all six degrees of freedom, when the segments immediately above and below a primary lesioned segment are examined.

Figure 7 illustrates the asymmetry throughout a fundamental unit of spinal segmental dysfunction. There is increasing tissue resistance to rotation right at the location of the primary motor asymmetry indicated at $\mathrm{T} 6$, with opposing asymmetries resisting rotation left at adjacent $\mathrm{T} 5$ and $\mathrm{T} 7$. Again, only axial rotation is indicated. When multiplied by six for the six degrees of limited freedom - three rotations and three translations-it becomes apparent that motion testing provides six variables to describe the individuality of a given unit of segmental dysfunction. Comparison testing for the mirror-image findings at adjacent segments confirms the location of the primary central segment for the medical record.

\section{Discussion}

The term "segmental definition"2 refers to the final stage, or level 3 , in an orderly sequence of diagnostic tests for somatic dysfunction. This sequencing of visual and palpatory tests for examining the somatic system is modeled after the classic approach for observing each of the body's systemic 


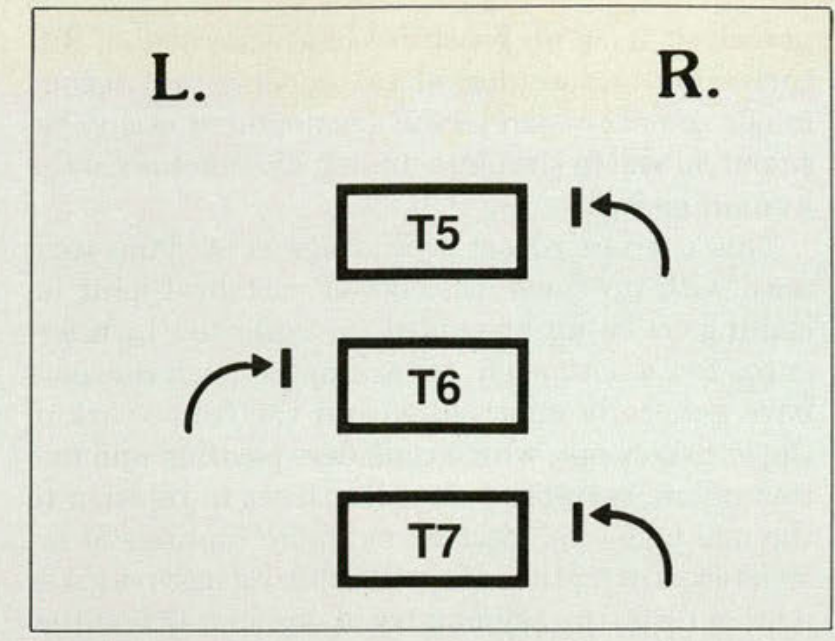

Fig. 7. Schematic representation of a fundamental unit of segmental dysfunction: A primary motor asymmetry is indicated as the central segment $T 6$, which resists rotation right, with opposing asymmetries at adjacent segments, which resist rotation left.

Fig. 8. A concept of mobile segments operating individually, and in concert, in response to demand for a gross movement within a mobile system.

functions during the regional physical examination.

In the somatic model, level 1 tests are used to screen for signs of asymmetry of structure, tissue, and motion throughout the body to determine if initial signs of dysfunction are present in the somatic system. Comparable level 1 tests in the cardiac system, for example, would include the intial screen for signs of irregularity of cardiac rate and rhythm and for alteration in the quality of the heart sounds.

Level 2 tests for the somatic system are designed to scan bony structures, soft tissues, and motion properties from point to point throughout a body region (identified in the screen), to determine a precise location of the dysfunction. Level 3 tests of segmental definition are used to examine at that location for the individual characteristics of bony malposition, tissue texture abnormality, and motion asymmetry that provide a diagnosis of segmental dysfunction, and justify consideration of treatment.

For perspective at this point, let us recognize that the soma participates in many of the body's functional systems: electric energy; fluid conduction; tissue interconnection; and, structural support functions. The diagnostic approach outlined here relates to the soma in its primary role as the body's skeletal movement system, and a test pattern for investigating aspects of that movement function is described. As introduced, the report only briefly references the kinds of diagnostic tests that screen the body for impressions of the presence of somatic dysfunction, or those that scan from point to point

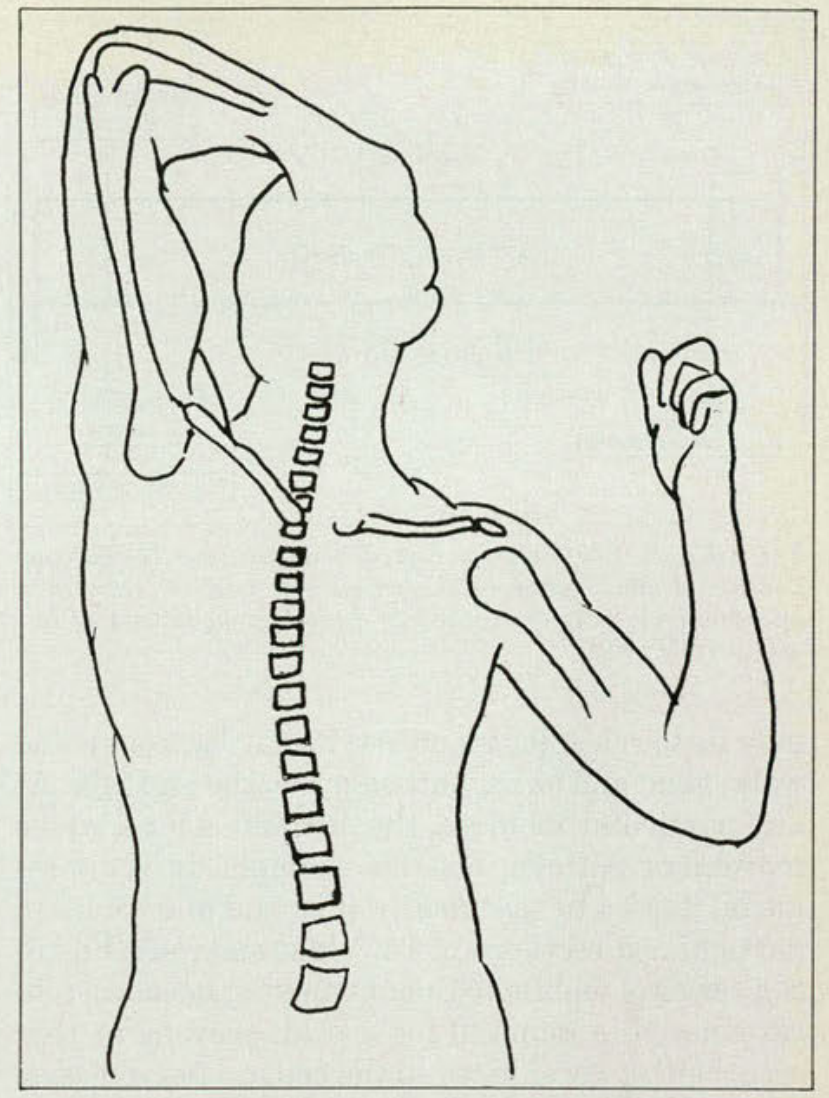

for precise location of dysfunction. Mainly, it details a framework of tests for defining the motion characteristics at a dysfunctional mobile segment.

The anatomic concept of a joint-one bone in relation to the one below-has often been useful for describing palpable findings of disturbed position and mobility at a spinal joint, but it has inherent limitations for study of segmental motion. Although the idea of body movement requires speculation about relationships of one bony part to another, the joint concept does not easily convey the functional dynamics of reception of stimuli, motor controls, and the part-to-whole relations that are basic to a human movement system. The joint concept may even be somewhat counterproductive, when part-to-whole relations in body movement function are the primary consideration-as they are in the examination procedures described here.

During active clinical practice, the study of this mobile system has involved our initial recognition and then application of the concept involved in the term "system." The term refers to any grouping of dynamically-related components (in this instance mobile segments) that operate in concert, or in related fashion, for the purpose of achieving a specified goal or set of goals (in this instance, movement). Together, mobile segments respond to a central demand for active whole-body movement. It 


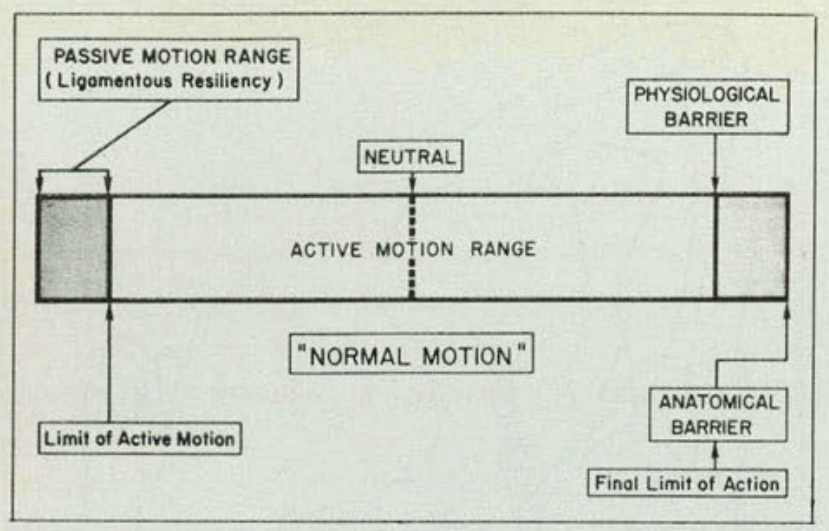

Fig. 9. Kimberly's" diagram reproduced here describes the components of joint motion by the physiologic barrier (resistance) and anatomic barrier reached by bone and ligaments. (From JAOA, April 1980.)

may be to reach for an object; it may be to step and walk, bend and twist, and even breathe and talk. At any particular moment, the demand is for a whole movement pattern, not, for example, in the joint model, for T4 to specifically sidebend and rotate in particular directions on T5. What emerges (Fig. 8) is a series of mobile segments moving in concert, in response to a demand for overall movement that essentially is organized in the central nervous system. A mobile segment can be described as a bone, with articular surfaces for movement, and the adnexal tissues that (1) stabilize position, (2) allow the bone to be moved from one position to another, and (3) initiate and carry out the response to movement.

In systems theory, these mobile segments may be referred to as "subsystems." The response of each mobile bony part is controlled in a major way on a segmental basis by local spinal reflexes of proprioceptive sensory origin. ${ }^{8}$ This sensory input provides ongoing feedback of information needed for fine tuning of the behavior of each subsystem, establishing spinal reflex motor control for each mobile segment to be in the right place at the right time in its relation to the whole movement pattern being performed. Significantly, spinal reflexes control (self-correct) each segment's response whether the gross movement is performed actively or within a framework of passive movement tests.

The foregoing description of palpable findings in the passively induced gross motion tests for response at a mobile segment (Fig. 4) adds a dimension of tissue tone (increment of compliance/ resistance) to Kimberly's ${ }^{11}$ more linear diagram of the restrictive barrier, reproduced in Figure 9.

Bowles ${ }^{12}$ was particularly fascinated with the hyperbolic aspect of the tissue resistance (bind) palpable during motion tests for the asymmetric behavior at a dysfunctional segment (Fig. 5). He perceived it as an essential characteristic of disturbed neuromusculoskeletal response that needed major consideration in the development of any research model to simulate motion dysfunction in the human body. ${ }^{13}$

This current report of findings is at some variance with previous concepts of vertebral joint lesioning as being one-sided (as reflected in references to T4 on the left, for example). Such concepts have gerierally emerged within the framework of the joint concept, which considers position and motion of one vertebra's articular facet in relation to the one below to describe palpable findings of restricted joint motion. However, during passive gross motion tests, the asymmetry of segmental dysfunction is palpable bilaterally. With the subject seated (Fig. 3), and registering resistance of the mobile unit to rotation of the shoulders and trunk to the right, resistance cues are palpable at tissues overlying both the right and left transverse processes. For this reason, sidedness of resistance is described only in relation to the direction of the motion being tested - for example, resisting rotation rightrather than in relation to left-sided locking or restriction of the joint's facet motion, which implies a conceptual cause of the increased resistance being palpated.

Further, the completeness of the pattern of asymmetric response to all six motion tests is at odds with one general classification of lesioned joints: type 1 describes contralateral restriction of lateral flexion and axial rotation, without restriction of either forward flexion or extension; and type 2 is ipsilateral restriction of lateral flexion and axial rotation, when accompanied by restriction of either forward flexion or extension.

The assumption originally made in this classification may have been related to Fryette's ${ }^{14}$ statements of physiologic motion in the spine. On face value, normal vertebral movement would not seem to offer a predictable basis for expectations of the findings at $d y s$ functional spinal segments. Another possible assumption is that this classification of type 1 and type 2 dysfunctions may have been related originally to group (lateral curve) and single (joint) kinds of spinal findings respectively. Certainly, the findings in a lateral spinal curve usually involve rotation of the bodies of the vertebrae into the convexity (contralateral to the lateral flexion). However, segments in a group curve usually offer a smooth sequence of behavior; they fulfill criteria for their group activity that are quite different from those for the lesioned behavior of individual segments described in this report for a fundamental three-segment unit, where adjacent segments show opposing asymmetries. The uniform segmental ac- 
tivities recognized as grouped within lateral spinal convexities are more appropriately classified as primary and secondary scolioses, rather than a series of type 1 dysfunctional segments.

The major issue here is that each fundamental unit of segmental dysfunction has a definable component of forward flexion/extension asymmetry when responses to these opposing directions of a motion test are compared. This feature helps to characterize the dysfunctional unit as totally asymmetric, that is, in all six degrees of freedom.

The definition of specific segmental asymmetries elicited during the test pattern described here begins to provide a description of segmental dysfunction as a clinical focus within the more general diagnostic category of somatic dysfunction. The findings suggest, in turn, a frame of reference for an approach to treatment and the evaluation of response to treatment. These factors will be elaborated in part II of this paper.

I am indebted to Albert F. Kelso, Ph.D., for his comments and assistance.

1. Siehl, D., chairman, Hospital Assistance Committee of the Academy of Applied Osteopathy. Recording of osteopathic diagnostic and therapeutic terms for office and hospital. The D.O. 11:209-10, Sep 70
2. Johnston, W.L.: Inter-examiner reliability studies. Spanning a gap in medical research-Louisa Burns Memorial Lecture. JAOA 81:819-29 Aug 82

3. Johnston, W.L., and Hill, J.L.: Spinal segmental dysfunction. Incidence in cervicothoracic region. JAOA 81:22-8, Sep 81

4. Johnston, W.L.: Passive gross motion testing. Part I. Its role in physical examination. JAOA 81:298-303, Jan 82

5. Johnston, W.L.: Manipulative specifics. JAOA 61:535-9, Mar 82

6. Johnston, W.L., Vorro, J. and Hubbard, R.P.: Clinical/biomechanic correlates for cervical function. A kinematic study. JAOA 85:429-37, Jul 85

7. Vorro, J., and Johnston, W.L.: Clinical biomechanic correlates for cervical functions, Part II. A myoelectric study. JAOA 87:353-67, May 87

8. Henneman, E.: Spinal reflexes and the control of movement. In Medical physiology, edited by V.B. Mountcastle. Ed. 13. C.V. Mosby Co., St. Louis, 1974, vol. 1

9. Bowles, C.H.: Functional orientation for technic-Part III. AAO Year Book, p. 56, 1957

10. Hoover, H.V.: Diagnosis and treatment of lesion patterns and complicated lesions. JAOA 52:553-5, Jul 53

11. Kimberly, P.E.: Formulating a prescription for osteopathic manipulative treatment. JAOA 79:506-13, Apr 80

12. Bowles, C.H.: Functional orientation for technic Part II. AAO Year Book, pp. 107-114, 1956

13. Bowles, C.H.: Personal communication

14. Fryette, H.H.: Principles of osteopathic technic. Academy of Applied Osteopathy, Carmel, California, 1954

Dr. Johnston is professor, Department of Family Medicine, Michigan State University - College of Osteopathic Medicine, East Lansing, Michigan.

Dr. Johnston, MSU-COM, West Fee Hall, East Lansing, Michigan 48824 . 


\section{OSTEOPATHIC RESEARCH:}

\section{GROWTH AND DEVELOPMENT}

- Where have we been?

- Where are we now?

- Where are we going?

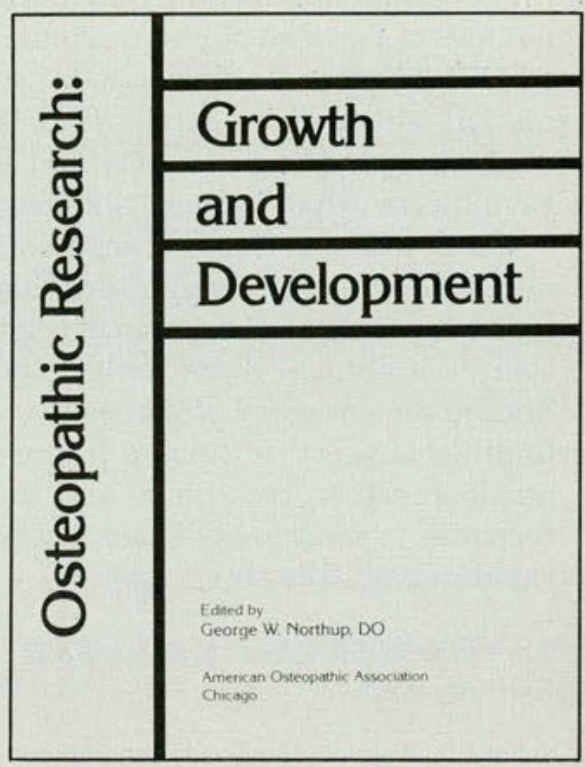

- General History-Wilbur V. Cole, DO

- Anatomical and Histopathological Evidence

-Wilbur V. Cole, DO

- Biomechanics-Myron C. Beal, DO

- Physiology —Albert F. Kelso, PhD

- Clinical Research-Myron C. Beal, DO

- Status and Future of Osteopathic Research

-Albert F. Kelso, PhD

Alexandra A. Townsend, DO

An excellent source for students, teachers, researchers, and practitioners.

Send check and order form to:

American Osteopathic Association

142 E. Ontario Street

Chicago, Illinois 60611

Attn: Order Department

Please send me: hardcover copies of Osteopathic Research: Growth and Development (\$11 each) 

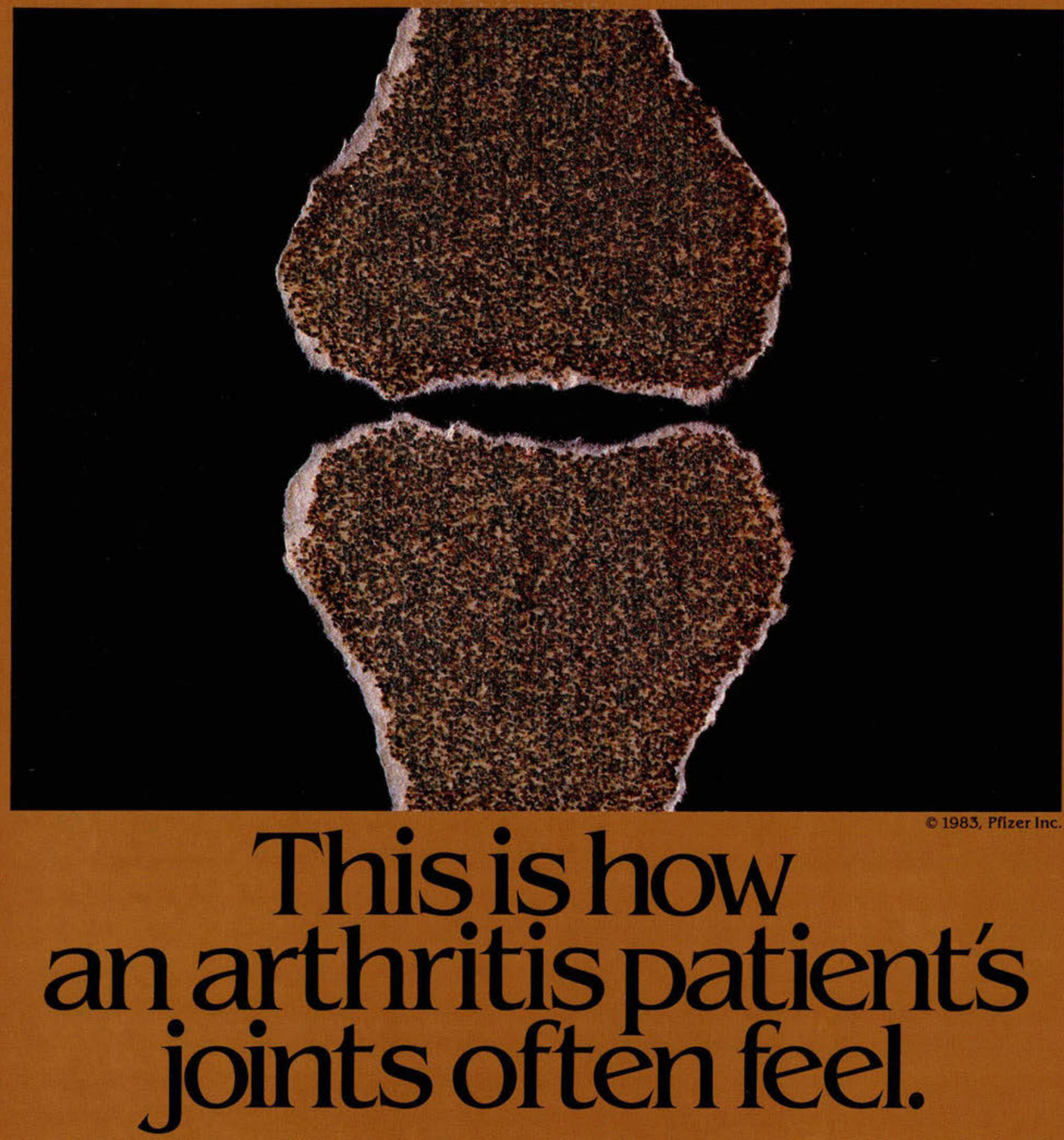

You can help these patients feel better with one-a-day FELDENE" (piroxicam). For good reasons:

- it's effective-proven relief of the pain and inflammation of rheumatoid arthritis and osteoarthritis ${ }^{1}$ in millions

of patients, in over 100 countries all around the world.

- it's efficient-once daily, 20-mg dose provides round-the-clock relief, improves compliance and remains effective during long-term therapy.

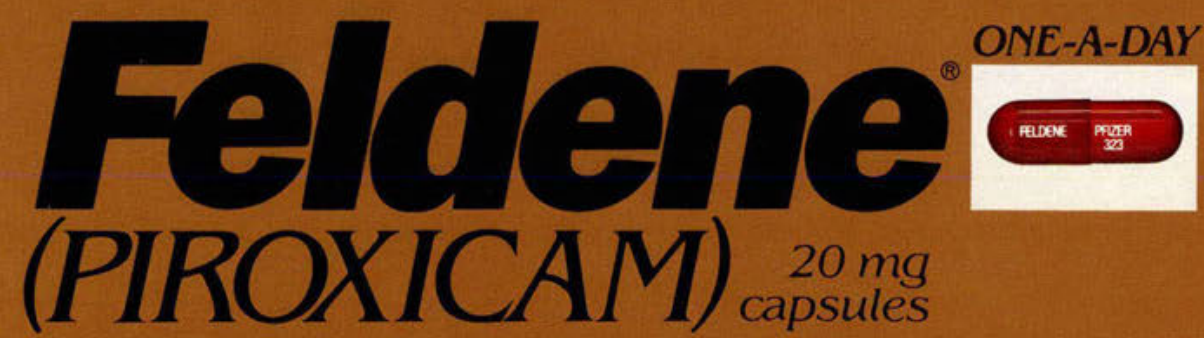

Please see FELDENE (piroxicam) brief summary on the following page. 


\section{Feldene (PIROXICAM) $)_{\text {apong }}^{2}$}

Prescribe one $20 \mathrm{mg}$ capsule daily for convenience and compliance

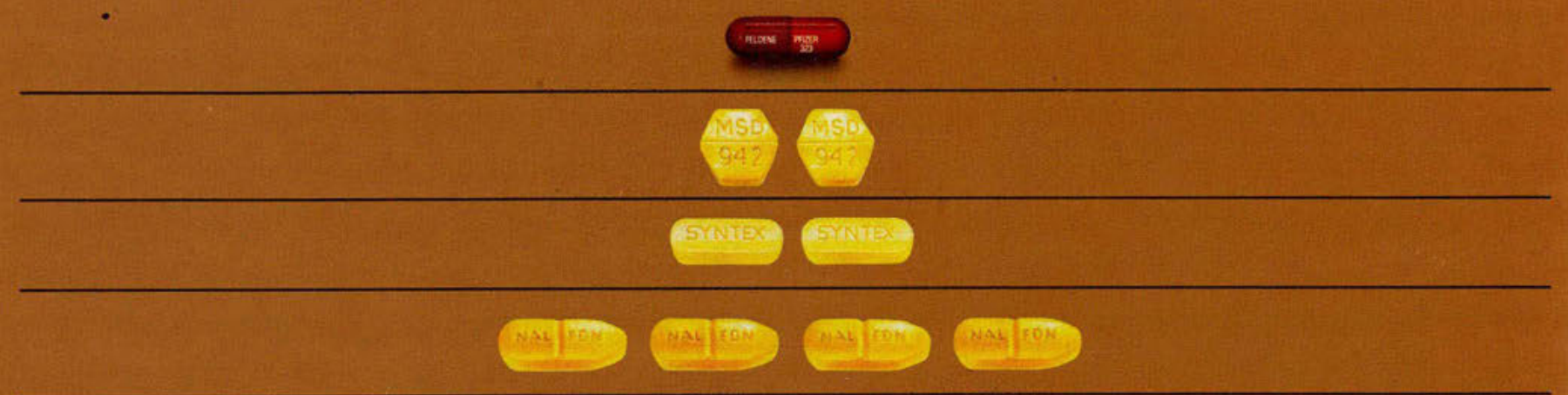

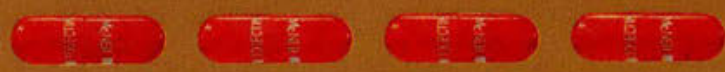

Source: PDR, 1987, Manufacturers' Prescribing Information. Indicates maximum dosage for osteoarthritis and rheumatoid arthritis for the antiarthritic agents shown. Consult manufacturers' prescribing information.

Brief Summary

FELDENE* (piroxicam) Capsules
CONTRAIMDICATIONS: FELOENE (Diroxicam) should not be used in patients who have previously exhibited hypersensitivity to it. or in individuals with the syndrome comprised of bronchospasm, nasal polyps and angioederma precipitated by aspith

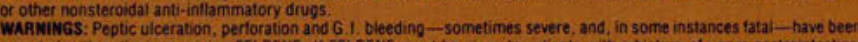
reported with patients receiving FELDENE. II FEL OENE must be given to patients with a history of upper gastrointestina tract disease, the patient should de under close supervision (see ADVERSE REACTIONS)

PRECAUTIONS: Renal Eflects. As with other nonsteroidal anti-inflammatory drugs, long-term administration of piroxican 10 animals nas resulted in renal papillary necrosis and other abnormal renal pathology in humans. there have been reports A sec interstitiat nephritis with hematuria, proteinura, and occasionaily, nephrotic syndrome

A second form of renal toxicity has been seen in patients with prerenal conditions leading to a reduction in renat bloos llow or biood volume, where the renal prostaglandins have a supportive role in the mantenacoce of renal perfusion. In these patients administration of an NSAIO may cause a dose-cependent reduction in prostaglandin formation and may precipitale
overt renal decompensation. Patients at greatest risk of this reaction are those with impaired renal function. heart falute fiver dystunction, those taking diuretics, and the elderly

Because of extensive renal excretion of piroxicam and its biotranstormation products fless than $5 \%$ of the daily dost excreled unchanged). lower doses of piroxicam should be anticipated in patients with impaired renal function, and the should be carelully monitored

Aithough other nonsteroidal anti-inflammatory drugs do not have the same direct eftect on platelets that aspirin does. all drugs inhibiting prostagtandin biosynthesis do intertere with platelet function to some degre:

Because of reports of adverse eye findings with nonsteroidal anti-intlammatory agents, it is recommended that patients who develop visual complaints during treatment with FELDENE have ophithaimic evaluation

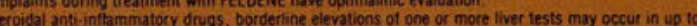
$15 \%$ of patients. A patient with symptoms andior signs suggesting liver dystunction, or in whom abnormal livet teste have occurred. should be evaluated for evidence of the develooment of more severe hiepatic reaction while on therapy with FELDENE

Severe hepatic reactions. including laundice and cases of tatat hepatitis have been reported with FELDENE. Athough such reactions are rare, if abnormal liver tests persist or worsen, if cinical signs and symptoms consistent with ilver dis ease develop, or it systemic manifestations occut (e.9. eosinophila, rash, etc), fELOENE should be discontinued. (Se: aISO ADVERSE REACTIONS.

Aithough at the recommended dose of $20 \mathrm{mg} / d a y$ of FELDENE increased fecal blood loss due to gastrointestinat inritation did not occur, in about $4 \%$ of the patients treated with FELDENE alone or concomitantly with aspirin, reductions in he

Peripheral edema has been observed in approximately $2 \%$ of the patients treated with FELDENE. Therefore, FELDENE should be used with caution in patients with heart tailure, hypertension or other conditions predisposing to lluid retention. A combination of dermatological and/or allergic signs and symptoms suggestive of serum sickness have occasionally
occurred in conjunction with the use of FELDENE. These include arthraloias, prustus, fever, fatigue. and rash inciuding vesiculo bullous reactions and extoliative dermatit

vesiculo bullous reactions and extoliative dermartis:
ORUG iwTERACTIONS: Interactions with coumarin-type anticoagulants have been reported with FEL DENE since marketing Therefore, physicians should closely monitor patients lor a change in dosage requirements when administering fELDER:

to patients on coumarin-type anticoagulants and other highly protein-bound drugs
Plasma levels of piroxicam are depressed to approximately $80 \%$ of their normal values when FELDENE is administered in conjunction with aspirin ( $3900 \mathrm{mp} / \mathrm{day}$ ), Dut concomitant administration of antacids has no etlect on piroxicam plasma

Nonsteroidal anti-intlammatory agents, including FELDENE, have been reported to increase steady state plasma lithium levels. It is recommended that plasma lithium leveis be monitored when initiating, adjusting and discontinuing FELDENE: Carcinogenesis, Chronic Animal Toxicity and Impairmeat of Fertility: Subacute and chronic toxicity studies have beer carried out in rats, mice. dogs, and monkeys

The pathology most often seen was that characteristically associated with the animal toxicology of anti-inflammatory agents: renat papiliary necrosis (see PRECAUTIONS) and gastrointestinal iesions.

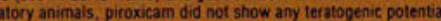

Pregnancr and Mursing Mothers: Like other defugs which inhibit the synthesis and release of orostaglandins, piroxican idministration continued late into pregnancy increased the incidence of dystocia and delayed parturition in animals. Gas trointestinal tract toxicty was increased in pregnant femaies in the last trimester of pregnancy compared to non-pregnan emales or temales in earlier trimesters of pregnanc.

FELOENE is not recommended for use in nursing mothers or in pregnant women because of the animal findings and sinct stety for such use has not been established in humar

Use in Children: OOsage recommendations and indications for use in children have not been established.
ADVERSE REACTIOWS: Gastrointestinal symntoms are the mately $20 \%$ ADVERSE REACTIOWS: Gastrointestinal symptoms are the most prominent side effects, occurring in approximately $20 \%$
of the patients. which in most instances did not interfere with the course of therapy. Of the patients experiencing oastro of the patients, which in most instances did not intertere with the course of therapy. Ot the patients expeniencing gass
intestinal side etiects. aporoximately $5 \%$ discontinued theragy with an overall incidence of peptic uiceration of about $1 \%$.
Adverse reactions are listed below by body system for all patients in clinical trials with fELOENE (piroxicam) at doses of $20 \mathrm{mg} / \mathrm{day}$

Incideace Greater Than 1\%: The following adverse reactions occurred more frequently than 1 in 100

Gastrointestinal: stomattos. anorexia, epigastric distress;' nausea: constipation, abdominal discomfort, tlatulence, of arthea, abdominal pain, indigestion

Hematological decreases in hemoglobin' and hematocrit" (see PRECAUTDONS). anemia, leucopenia, eosinophila

Dermatologic: prunitus, nas

Centrai Nervous System diziness, somnolence, vertipo

(SER PRECAUTIONS)

Sody as a Whole headach

Cardiovascular RiRnitus

Reactions occurnng in $3 \%$ to $9 \%$ of patients treated with FELDENE

Reactions occurring in $1 \%$ to $3 \%$ of patients are unmatkec

Incidence Less Than $1 \%$ (Causal Relationship Probabie): The following adverse reactions occurred less frequently than 1 in 100 . The probability exists that there is a causal relationship between fELOENE and these reactions

Gastroinfestinal: liver function abnormalities, pundice, hepattis (see PRECAUTIONS), vorniting, hematemesis, melens gastrointestinal bleeding. Dertoration and uiceration (see WARNINGS); ory mouth

Hematological thrombocytopenia, petechial rash, ecchymosis, bone marrow depression including aplastic anemia

Dermatologic sweating, erythema, bruising, desquamation, extoliative dermatitis, erythema multuforme, toxic epider mal necroiysis, Sievens J Jahnson syndrome, vesiculo bullous reactions, photoallergic skin reactions

Urogenitat: hematuria, proteinuria. interstitial nephritis. renal failure. Ayperikalemia. glomerulitis, papillary necrosis nephrotic syndrome (see PRECAUTIONS)

Body as a Whole pain (colic), tever, flu-like syndrome (see PRECAUTIONS)

Special Senses - swollen eyes, blurred vision, eye irritations

Cardiovascular:Respiratory, hypertension, worsening of congestive heart failute (see PRECAUTIONS), exacerbation of ingins

Metabolic hypoglycema, hyperglycemia, weight increase, weight decrease

Hypersensitivity anaphylaxis, bronchospasm, urticaria angioedema, vasculitis, "serum sickness' (set PRECAUTIONS)

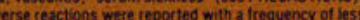
than 1 in 100 . but a causal relationship between FELDENE and the reaction could not be determined

Gastrointectinat mancreating

Dermatoiogic onycholysis loss of hain

Cuntral Nervous System: akathicia, haltucinations mood alterations dream abnotmatities, mental contusion. paresthesia:

cody as a Whole: weakness

Cardiovascular Respiratory palpitations, dyspne.

Hypersensitivity: positive Awa

Sopcial Senses heaing impairnent
OVERDOSAGE: In the event treatment for overdosage is required, the long plasma halt-life of piroxicam should be consid:

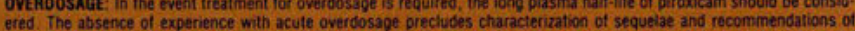
specific antidotal efficacy at this time. It is reasonable to assume that the standard measures of gastric evacuation and peneral supportive theragy would apoily in addition to supportive measures the use of activated charcoal may effectively ceduce the absorption and reabsorption of piroxicam. Experiments in dogs have demonstrated that the use of multiple-dos: treatments with activated charcoal could reduce the half life of piroxicam elimination from 27 hours (without charcoail) in 11 hours and reduce the systemic bioavailabelity of piroxicam by as much as $37 \%$ when activated charcoal is given as late

as 6 hours atter administration of piroxicarn.
ADMINISTRATION AND DOSAGE: Rheumatoid Arthritis, Osteoarthritis: It is reconmended that FELDENE therapy be ini. tiated and maintained at a single daily dose of $20 \mathrm{mg}$. If desired, the daliy dose may be dividec.

Dosage secommendations and indications for use in children have not been established.

More setailed professionat information available on request

C1982, Pfizer Inc Reterences: 1 Siegmeth W: Serum concentrations of piroxicam in relation to its clinical effect in patients with chronic po-
ivarthntis (trans). Wien Med Wochenschr 130:31-35. 1980.2. Tausch: Placebo-controlled study of piroxicam in the freat: ment of meumatoid arthritis. Am J Med (reporti) 72:18-22. February 16. 1982 